\title{
Study on the culture of Escherichia coli with different hydrolysis depth of globin
}

\author{
SONG Zurong ${ }^{1}$, TAO Ali ${ }^{1}$, FENG Xuehua ${ }^{1}$ \\ ( ${ }^{1}$ School of Pharmacology, Anhui Xinhua University, Hefei 230088, China)
}

\begin{abstract}
Objective: To explore the effect of culture medium made of peptide fragments of different sizes of globin hydrolyzed by protease on the culture of Escherichia coli.

Method: with fresh pig blood as raw material, hydrolyze pig blood protein under fixed conditions, and screen out the enzyme with the highest degree of hydrolysis. Then conduct orthogonal test on the enzyme to determine the best hydrolysis conditions; the beads were obtained under the best hydrolysis conditions. The Escherichia coli was cultured on different peptone culture bases that were prepared by hydrolysate going through different pore size ultrafiltration membrane samples. The culture of Escherichia coli at different hydrolysis depths is determined by detecting the total amount with Escherichia coli detection method.

Results: Trypsin has the best hydrolysis effect. The best hydrolysis conditions are as follows: enzyme dosage of $0.2 \%$, hydrolysis time of $12 \mathrm{~h}$, temperature of $50^{\circ} \mathrm{C}$, initial $\mathrm{pH}$ of 7.5 and mass fraction of substrate protein of $8 \%$. Through growth curves of Escherichia coli, it is known that the smaller the pore size of the ultrafiltration membrane, the smaller the molecular weight of the peptide fragment, and the greater the density of the Escherichia coli bacterial solution.

Conclusion: Through analyzing the production curves of Escherichia coli in different culture medium, it is concluded that the smaller the molecular weight of the protein peptides, the higher the density of Escherichia coli solution in the LB liquid medium prepared by it, and the better the Escherichia coli culture effect.
\end{abstract}

\section{Introduction}

In the processing and utilization of pig blood, except that a small part is used for food addition, most of it is discharged as waste, which not only pollutes the environment, but also wastes protein resources ${ }^{[1]}$. Therefore, we need to make use of pig blood, especially fresh pig blood. It can be decomposed into globin and other substances, and then made into polypeptides needed in the food and pharmaceutical industries through hydrolysis reaction. Polypeptides can form a transparent powder of after being concentrated and dried ${ }^{[2,3]}$. The peptone contains a lot of amino acids, and more vitamins and other growth factors, which are extremely beneficial to the growth of bacteria such as Escherichia coli and can be used to provide basic raw materials, nitrogen sources, vitamins and other nutrients for the culture of it, which not only improves the utilization rate of pig blood resources, but also accelerate the progress of Escherichia coli culture research ${ }^{[4-6]}$.

\section{Test materials and methods}

\subsection{Materials and instruments}

Fresh pig blood (specified pig slaughterhouse in Hefei Economic and Technological Development Zone); trypsin, flavor zyme, neutral protease (Beijing Ruida Henghui Technology Development Co., Ltd.); electric-heating thermostatic water bath HWS28, drying oven DHG-9240A (Shanghai Yiheng Science Instrument Co., Ltd.); Magnetic stirrer SH-3 (Beijing Nuocheng Jiaxin Instrument Co., Ltd.) Constant temperature shaker HASUC (Shanghai Instrument Manufacturing Co., Ltd.); Spectrophotometer V-1100D (Shanghai Meipuda Instrument Co., Ltd.).

\subsection{Method}

\subsubsection{Initial screening of protease}

Design different proteases to hydrolyze pig blood separately. Set the mass fraction of substrate protein in the solution as $8 \%$, and hydrolyze them for 6 hours with the optimal temperature $\mathrm{pH}$ value. Use formaldehyde titration to measure the amino acid content of the hydrolyzed supernatant.

(1) Take $200 \mathrm{~mL}$ of formaldehyde and put it in a beaker. Use $\mathrm{NaOH}$ standard solution to adjust the $\mathrm{pH}$ to 8.2 during electromagnetic stirring.

(2) Put $5 \mathrm{~mL}$ of the solution to be tested in a beaker, and add $60 \mathrm{~mL}$ of distilled water to boil, degas and cool. Then adjust the $\mathrm{pH}$ to 8.2 with $0.01 \mathrm{~mol} / \mathrm{L} \mathrm{NaOH}$, and retain for 30 seconds.

(3) Add $20 \mathrm{~mL}$ of the prepared formaldehyde solution in a slow way and use $\mathrm{NaOH}$ standard solution to measure the $\mathrm{pH}$ of the solution to 9.2 after a magnetic 
stirring for 3 minutes, then record the volume of $\mathrm{NaOH}$ consumed $\mathrm{V}_{1}$; use distilled water as a blank control and record the volume of $\mathrm{NaOH}$ consumed $\mathrm{V}_{2} .1000 \times \mathrm{C} \times\left(\mathrm{V}_{1}\right.$ $-\mathrm{V}_{2}$ )

(4) Amino acid content of the liquid to be tested

Amino content $=200 \times \mathrm{C} \times\left(\mathrm{V}_{1}-\mathrm{V}_{2}\right) ; \quad \mathrm{C}$ : the concentration of $\mathrm{NaOH}$ used in the measurement

DH/\% = The amino acid in the Hydrolyzed supernatant $* 100 \%$

sample before hydrolysis

Total nitrogen in the

\subsubsection{Study on the best conditions for trypsin hydrolysis of globin}

The globin is hydrolyzed by single factor control of hydrolysis time, hydrolysis temperature, enzyme dosage, initial $\mathrm{pH}$ value and other variables, and then obtain the optimal hydrolysis conditions for trypsin hydrolysis of globin by orthogonal test, as shown in Table 1.

Table 1 Factor level table

\begin{tabular}{ccccc}
\hline & $\begin{array}{c}\text { A (Enzyme } \\
\text { dosage } \%)\end{array}$ & $\mathrm{B}(\mathrm{h})$ & $\mathrm{C}\left({ }^{\circ} \mathrm{C}\right)$ & $\mathrm{D} / \mathrm{PH}$ \\
\hline 1 & 0.2 & 11 & 45 & 7.5 \\
2 & 0.3 & 12 & 50 & 8.0 \\
3 & 0.3 & 13 & 55 & 8.5 \\
\hline
\end{tabular}

\subsubsection{Study on the preparation of different peptide filtrates}

Add $0.35 \%$ sodium citrate solution into fresh pig blood, and remove the serum by centrifugation. Add water of the same volume as red blood cells, then stir and mix the hemolysis to adjust the protein concentration of the reaction solution to $8.0 \%$, and start hydrolysis under the above optimal hydrolysis conditions. After the reaction has stopped, heat and boil for another 10 minutes, then adjust the $\mathrm{pH}$ to 5.0 , and take the supernatant for use after centrifugation.

Take an equal amount of the homogenized globin hydrolysate and put them through ultrafiltration membrane samples with different pore sizes of 5000Da, $10000 \mathrm{Da}, 20000 \mathrm{Da}, 1 \mathrm{~nm}$, and $10 \mathrm{~nm}$, and detect the free amino acid content and dry matter content in the filtrate.

\subsubsection{Measurement of free amino acid content}

Take $12.5 \mathrm{ml}$ of the filtrate sample and put it into a volumetric flask of $250 \mathrm{ml}$. Make a uniform mixing, then draw $20.0 \mathrm{ml}$ of the diluted filtrate and put it into a beaker of $250 \mathrm{ml}$ and add $60 \mathrm{ml}$ of water to re-dilute. Insert the glass electrode and mercury electrode, then turn on the magnetic stirrer, and titrate the solution in the beaker with $\mathrm{NaOH}$ standard volumetric solution until the $\mathrm{pH}$ value is 9.2 . Then add $10.0 \mathrm{ml}$ formaldehyde solution, and titrate it to the acidity $\mathrm{PH}$ value of 9.2 with $\mathrm{NaOH}$ standard volumetric solution. Record the volume of the solution as V1at the moment.

In addition, take $80 \mathrm{ml}$ water and adjust the $\mathrm{pH}$ to 8.2 with $\mathrm{NaOH}$ solution. Titrate it with the above steps and take down the volume of the sodium hydroxide standard solution consumed as V2 for the reagent blank control test.

Calculation

$$
X=\frac{\left(V_{2}-V_{1}\right) \times C_{1} \times 0.014}{V_{3} \times \frac{12.5}{250}}
$$
filtrate;

In which, $\mathrm{X}-$ the content of amino nitrogen in the

$\mathrm{V} 1$ - the volume of $\mathrm{NaOH}$ standard volumetric solution consumed after adding formaldehyde into the sample diluent for measurement, $\mathrm{ml}$;

V2 - the volume of $\mathrm{NaOH}$ standard volumetric solution consumed in reagent blank test after adding formaldehyde, $\mathrm{ml}$;

$\mathrm{ml}$;

V3 - the amount of sample diluent taken, volumetric solution;

0.014 - the mass of nitrogen equivalent to $1.00 \mathrm{ml} \mathrm{NaOH}$ standard volumetric solution, g;

\subsubsection{Measurement method of dry matter content}

(1) Put the glassware in the oven. Heat it at $100^{\circ} \mathrm{C}$ for $4 \mathrm{~h}$, then take it out and put it in a drying oven for cooling. Weigh it after cooling for half an hour, which is $\mathrm{m} 1$.

(2) Weigh a certain amount of filtrate in a glassware. Now the total weight of the glassware and the sample to be tested is $m 2$, then put it in an oven and heat it at $100^{\circ} \mathrm{C}$. Taking it out 4 hours later and put it in a drying oven to cool for half an hour, then weigh and mark it as $\mathrm{m} 3$.

(3) Calculation: $\mathrm{DM}=(\mathrm{m} 3-\mathrm{m} 1) /(\mathrm{m} 2-\mathrm{m} 1)$

\subsubsection{Study on culture of Escherichia coli with different peptone media}

With single factor experiment, calculate the dosage through dry matter. Keep other ingredients unchanged and change peptone. Prepare different medium to cultivate Escherichia coli. Use a spectrophotometer to accurately measure the cell density at $600 \mathrm{~nm}$ wavelength to compare curves of the culture of Escherichia coli in them. Use the cell density value of bacterial liquid to compare the effect of hydrolysis depth (different peptone) on Escherichia coli culture.

\subsubsection{Methods of preparation of different peptones}

Pass the hydrolyzed globin solution through ultrafiltration membrane samples of 5000Da, 10000Da, 
20000Da, $1 \mathrm{~nm}$ and10nm. Take filtrates that penetrates the membrane for use, and record them as filtrate A, B, C, $\mathrm{D}$, E; pass the five filtrates through reverse osmosis membrane separately, desalting, concentrating and spray-drying so that light yellow transparent powder can be obtained, which are respectively peptone A, B, C, D, E. With single factor experiment, prepare five groups of culture medium. With other components in the culture medium unchanged, add peptone $\mathrm{A}, \mathrm{B}, \mathrm{C}, \mathrm{D}, \mathrm{E}$ to each medium respectively; five groups of different $\mathrm{LB}$ liquid mediums are obtained, which are LB liquid medium A, B, C, D, E for use.

\subsubsection{Method for preparing Escherichia coli culture medium}

(1) Centrifuge the liquid culture medium of the bacteria, then add an equal amount of $40 \%$ glycerol to the pellet, and freeze it at $80^{\circ} \mathrm{C}$ below zero.

(2) Preparation of solid medium

LB solid medium formula: peptone $10 \mathrm{~g} / \mathrm{L}$ yeast extract $5 \mathrm{~g} / \mathrm{L} \quad \mathrm{NaCl}$ solid $5 \mathrm{~g}$

water

$1000 \mathrm{ml}$

agar $15-20 \mathrm{~g}$

(3) Preparation of plates

Take $10.0 \mathrm{~g}$ of peptone, $5.0 \mathrm{~g}$ of yeast powder, $10.0 \mathrm{~g}$ of $\mathrm{NaCl}$, and $800 \mathrm{ml}$ of water to dissolve it for the second time, and stir it with a glass rod. Adjust the $\mathrm{pH}$ to about 7.4 with $1 \mathrm{~mol} / \mathrm{L} \mathrm{NaOH}$ solution, dilute it to $1 \mathrm{~L}$, and adjust its $\mathrm{pH}$ to 7.4. Pour the above solutions into different conical flasks, about $10 \mathrm{~cm}$ above the bottom of the flask, and then add agar of $2 \%$. Use a high-pressure steam sterilizer to sterilize them at $120^{\circ} \mathrm{C}$ for 15 minutes, then take out the culture medium and put them into an electric blast dryer to dry them at $60^{\circ} \mathrm{C}$. Pour them into the culture dishes with each containing about $10 \mathrm{ml}$. Conduct plate application on the aseptic operating table after condense.

(4) Inoculate Escherichia coli

Take the Escherichia coli BL21 cryopreservation solution prepared for the experiment, and burn the tube opening with an alcohol lamp, then open the centrifuge tube; put $100 \mathrm{ml}$ of the solution on the plate with a pipette, and then conduct plate application with a sterilized smear stick drawing cross.

(5) Culture of Escherichia coli

Put the inoculated plate upside down in a thermostatic incubator at $37^{\circ} \mathrm{C}$, and cultivate for 20 hours to grow colonies. Carry out the inoculation in a freshly sterilized LB liquid medium at $37^{\circ} \mathrm{C}$ with $229 \mathrm{rpm} / \mathrm{min}$ in thermostatic shaking for 10 hours. Then cultivate Escherichia coli in LB liquid medium A, B, C, D, and E respectively.

\subsubsection{Method for measurement of cell density of Escherichia coli bacteria solution}

Take the above-mentioned culture medium and number them as cell suspension A, B, C, D and E; put them into sterile test tubes numbered $\mathrm{A}, \mathrm{B}, \mathrm{C}, \mathrm{D}, \mathrm{E}$ respectively, and measure their absorbance value at wavelength of
$600 \mathrm{~nm}$; after shaking up the above cell suspensions at different concentrations, measure their OD values in a cuvette of $1 \mathrm{~cm}$ with wavelength of $600 \mathrm{~nm}$. In the colorimetric measurement, the culture medium without added bacteria can be used as a blank control to measure the OD value of 5 cell suspensions. Compare the growth of thermostatic in five different media with growth curves.

\section{Results and analysis}

\subsection{Analysis of the results of protease screening}

With the degree of hydrolysis as an indicator, calculate the hydrolysis degrees of above four enzymes (flavor protease $\mathrm{A}$, trypsin $\mathrm{B}$, compound protease $\mathrm{C}$, and neutral protease D), as shown in Table 2.

Table 2 Hydrolysis degree table of different

enzymes

\begin{tabular}{lllll}
\hline $\begin{array}{l}\text { Enzyme } \\
\text { type }\end{array}$ & $\mathrm{A}$ & $\mathrm{B}$ & $\mathrm{C}$ & $\mathrm{D}$ \\
\hline $\mathrm{DH} / \%$ & 27.85 & 39.80 & 18.05 & 23.40 \\
\hline
\end{tabular}

According to the table, among the four enzymes, the degree of hydrolysis is that flavor protease A (27.85), trypsin B (39.80), compound protease C (18.05), and neutral protease D (23.40). The highest degree of hydrolysis is trypsin, that is, Trypsin is selected as the suitable enzyme.

\subsection{Analysis of orthogonal experiment results}

Table 3 Orthogonal experiment table

\begin{tabular}{cccccc}
\hline & $\mathrm{A}(\%)$ & $\mathrm{B}(\mathrm{h})$ & $\mathrm{C}\left({ }^{\circ} \mathrm{C}\right)$ & $\mathrm{D} / \mathrm{PH}$ & $\%$ \\
\hline 1 & 0.2 & 11 & 45 & 7.5 & 41.20 \\
3 & 0.2 & 12 & 50 & 8.0 & 50.33 \\
4 & 0.2 & 13 & 55 & 8.5 & 43.25 \\
5 & 0.3 & 11 & 50 & 5.5 & 38.50 \\
6 & 0.3 & 12 & 55 & 7.5 & 51.02 \\
7 & 0.4 & 13 & 45 & 8.0 & 39.38 \\
8 & 0.4 & 12 & 55 & 8.0 & 35.65 \\
9 & 0.4 & 13 & 50 & 7.5 & 5.5 \\
$\mathrm{~K} 1$ & 44.93 & 38.45 & 39.34 & 49.11 & - \\
$\mathrm{K} 2$ & 42.97 & 46.27 & 47.98 & 41.79 & - \\
$\mathrm{K} 3$ & 42.73 & 45.91 & 43.31 & 39.73 & - \\
\hline & 2.2 & 7.82 & 4.67 & 9.38 & - \\
\hline & & & & & \\
\hline
\end{tabular}

According to the analysis of orthogonal table, obtain the 
best hydrolysis conditions for trypsin hydrolysis of globin, as shown in Table 3.

According to the range value of $\mathrm{R}$, it is known that the primary and secondary order is $\mathrm{D}>\mathrm{B}>\mathrm{C}>\mathrm{A}$, and the order of influencing factors is initial $\mathrm{pH}>$ hydrolysis time>temperature $>$ enzyme dosage; the optimal order is A1B2C2D1, and the optimal hydrolysis conditions are: initial $\mathrm{pH}$ of 7.5 , hydrolysis time of $12 \mathrm{~h}$, hydrolysis temperature of $50{ }^{\circ} \mathrm{C}$, enzyme dosage of $0.2 \%$.

\section{3.esult analysis of Escherichia coli growth curves}

The growth effect of Escherichia coli can be compared with the cell density value of the bacterial solution. The figure shows growth curves of Escherichia coli in different culture media. Escherichia coli cell suspension $(\mathrm{A}, \mathrm{B}, \mathrm{C}, \mathrm{D}, \mathrm{E})$

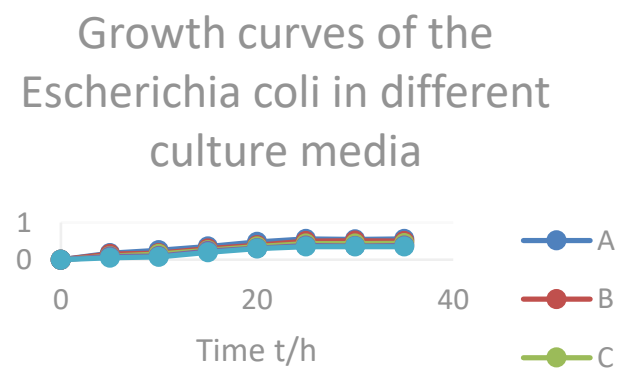

Figure 1 Growth curve of Escherichia coli in different culture media

From the OD value of Escherichia coli cell suspension (A, B, C, D, E), the growth of Escherichia coli in different media is clear to see. The excellent culture effect of Escherichia coli cell suspension is $\mathrm{A}>\mathrm{B}>\mathrm{C}>\mathrm{D}>\mathrm{E}$; the smaller the pore size of the ultrafiltration membrane, the smaller the molecular weight of the peptide, and the greater the density of Escherichia coli bacteria solution, that is, the better the growth of Escherichia coli.

\section{Conclusion}

The experiment results show that pancreatin has the best hydrolysis effect as the hydrolytic enzyme. With single factor and orthogonal experiments, it is obtained that the optimal hydrolysis conditions are: initial $\mathrm{pH}$ of 7.5 , hydrolysis time of $12 \mathrm{~h}$, hydrolysis temperature of $50^{\circ} \mathrm{C}$, enzyme dosage of $0.2 \%$, and mass fraction of substrate protein of $8 \%$. Hydrolyze globin under the optimal process conditions, and prepare protein peptide solutions of different molecular weights through ultrafiltration membrane samples of different pore sizes, then calculate the dosage through dry matter, and cultivate Escherichia coli in different LB liquid media with other ingredients unchanged. Finally, accurately measure the density of E. coli cells at a wavelength of $600 \mathrm{~nm}$ with a spectrophotometer to compare the effects of Escherichia coli culture. From the growth curves of Escherichia coli in different media, it is concluded through analysis that the smaller the molecular weight of protein peptides, the greater the density of Escherichia coli cultured in LB liquid medium prepared from it, that is, the better the effect of Escherichia coli culture.

\section{Acknowledgements}

This work was supported byNatural Science Research Foundation of the Department of Education of

Anhui Province (No.KJ2018A0583, KJ2019A0874),

Scientific research team of Anui Xinhuauniversity (kytd201908),

Quality engineering project of Anhui Xinhua University (2019xqjdx03 , 2019jxjy45),

University level scientific research project of Anhui Xinhua University (2017zr010).

\section{References}

1. Yu F M, YU H ZH,Jiang W B. Research Progress on the application of pig blood deep processing products in meat products[J]. research on rabbit meat products, 2011(7):37-40.

2. Miao J Y,Zhu,X M,Shao H Y, et al..Preparation of hydrolyzed protein and heme from pig blood by enzymatic technology,2011(7):125-128.

3. Wei L H,Shi Y W,Jiang W B, et al.Extraction of heme from blood residue of preparation of hemoglobin peptide[J].Food industry technology,2013,34(15):370-375.

4. Yang W G,Wang W D,Sun H G, et al.Preparation of heme rich peptide from porcine hemoglobin by complex enzyme hydrolysis[J].food science,2011,32(6):7-10.

5. Liu F,Xiao K,Wang X,et al.Separation and purification of pig blood protein from pig blood by ultrafiltratio[J].Journal of Biology,2011, 28(2):95-97.

6. $\mathrm{Gu} \mathrm{R}$ Z,Liu Y,Lin F,et al.Application of protein hydrolysates in animal cell cultu[J].Biotechnology Bulletin,2012(9):21-27. 